\title{
APLIKASI MODEL VECTOR AUTOREGRESSIVE (VAR) PADA DATA TAMU MANCANEGARA DI HOTEL BINTANG DAN NON BINTANG DI DAERAH ISTIMEWA YOGYAKARTA
}

\author{
Pardomuan Robinson Sihombing ${ }^{1, \text { a) }}$, Bekti Endar Susilowati ${ }^{2, b)}$ \\ ${ }^{1}$ Badan Pusat Statistik, Jalan Dr. Sutomo No 6-8, Jakarta Pusat \\ ${ }^{2}$ Badan Pusat Statistik Kabupaten Sleman, Jl. Purbaya, Mlati, Kabupaten Sleman, Yogyakarta. \\ Email: ${ }^{\text {a)robinson@bps.go.id, }}{ }^{\text {b) }}$ bekti@bps.go.id
}

\begin{abstract}
The Vector Autoregressive (VAR) model is a combination of several Autoregressive (AR) models, in which the model forms a vector whose variables influence each other. Model AR (1) states that current time observations are influenced by observations of one time before and the element of error. In this analysis, the Vector Autoregressive (VAR) model is used on the monthly data of foreign guests staying at star and non-star Hotels in the Special Region of Yogyakarta per month from January 2008 to December 2015. VAR model formation through several stages, namely: stationarity test, autoregressive order determination, VAR model formation, and diagnostic checking. Data processing in this study uses the $\mathrm{R}$ 3.5.1 program. From the data analysis, the variable number of foreign tourists in star and non-star hotels in Yogyakarta has a relatively high correlation of 0.91. With the Vector Autoregressive (VAR) model, VAR (1), the two significant simultaneous equation results are obtained. The R2 and Adjusted R2 values of the two partial equations of the VAR model (1) are quite high, namely, for the Star Hotel variable equation, R2 is $71.13 \%$, and Adjusted R2 is 70.5\%. In contrast, for the Non-Star Hotel variable equation, R2 is $76.56 \%$ and Adjusted R2 70.65\%.
\end{abstract}

Keywords: VAR, international tourist, star-hotel, non-star-hotel

\begin{abstract}
Abstrak
Model Vector Autoregressive (VAR) merupakan gabungan dari beberapa model Autoregressive (AR), dimana model membentuk sebuah vektor yang antara variabel-variabelnya saling memengaruhi. Model AR(1) menyatakan bahwa pengamatan waktu sekarang dipengaruhi pengamatan satu waktu sebelumnya dan unsur error. Pada analisis ini, model Vector Autoregressive (VAR) digunakan pada data tamu mancanegara per bulan yang menginap di Hotel Bintang dan Non bintang di Daerah Istimewa Yogyakarta per bulan periode Januari 2008 sampai dengan Desember 2015. Pembentukan model VAR
\end{abstract}


melalui beberapa tahap yaitu: uji stasioneritas, penentuan orde autoregressive, pembentukan model VAR, dan diagnostic checking. Untuk pengolahan data dilakukan dengan program R 3.5.1. Dari analisis data, variabel jumlah tamu wisatawan mancanegara di Hotel Bintang dan Hotel Non Bintang di Daerah Istimewa Yogyakarta memiliki korelasi yang cukup tinggi yaitu sebesar 0,91. Dengan model Vector Autoregressive (VAR) yaitu VAR(1) didapatkan kedua hasil persamaan simultan yang signifikan. Nilai $\mathrm{R}^{2}$ dan Adjusted $\mathrm{R}^{2}$ kedua persamaan parsial model VAR(1) cukup tinggi yaitu untuk persamaan variabel Hotel Bintang didapatkan R2 sebesar 71,13\% dan Adjusted R2 70,5\%, sedangkan untuk persamaan variabel Hotel Non Bintang didapatkan $\mathrm{R}^{2}$ sebesar 76,56\% dan dan Adjusted $\mathrm{R}^{2} 70,65 \%$.

Kata-kata kunci: Vector Autoregressive (VAR), tamu mancanegara, hotel bintang, hotel non bintang

\section{PENDAHULUAN}

Daerah Istimewa Yogyakarta yang dikenal dengan kota pelajar, kota budaya, dan kota wisata menjadikan Yogyakarta banyak diminati wisatawan untuk berkunjung. Tidak mengherankan bahwa jika setiap tahunnya jumlah kunjungan wisatawan baik wisatawan mancanegara (wisman) maupun wisatawan nusantara (wisnus) yang datang terus meningkat. Terkait dengan keadaan tersebut, pembangunan Hotel Bintang maupun Hotel Non Bintang pun terus meningkat untuk memenuhi kebutuhan hunian wisatawan.

Jumlah wisatawan khususnya mancanegara yang menginap di Hotel Bintang tahun 2015 mengalami kenaikan sebesar 16,06\% dibandingkan tahun 2014, sedangkan di Hotel Non Bintang mengalami peningkatan sebesar 40,78\% dibanding tahun 2014. Peningkatan jumlah wisatawan yang menginap di Hotel Non Bintang mengalami kenaikan yang lebih tinggi daripada yang menginap di Hotel Bintang. Menurut Sekretaris Perkumpulan Hotel dan Restauran Indonesia (PHRI) Daerah Istimewa Yogyakarta (Metrotvnews.com, Selasa, 01 Sep 2015) para wisatawan mancanegara lebih senang tinggal di hotel non bintang agar lebih murah dan tinggal lebih lama, serta menyatu dengan masyarakat setempat. Rata-rata lama tinggal tamu wisatawan mancanegara di Hotel Bintang pada tahun 2015 sebesar 2,01 hari yang berarti mengalami penurunan sebesar 0,02 hari dibanding tahun 2014 sebesar 1,99 hari, sedangkan rata-rata lama tinggal di Hotel Non Bintang di Daerah Istimewa Yogyakarta tahun 2015 sebesar 1,79 hari, yang berarti mengalami kenaikan sebesar 0,05 hari dibanding tahun 2014 yaitu 1,74 hari. Namun demikian, pada saat-saat tertentu, jika tingkat hunian Hotel Bintang tinggi (penuh), biasanya wisatawan akan beralih ke Hotel Non Bintang. Demikian pula jika wisatawan menginginkan fasilitas akomodasi Hotel Bintang, biasanya wisatawan mancanegara akan beralih ke Hotel Bintang.

Untuk kepentingan analisis dan prediksi, digunakan salah satu model multivariate time series yaitu Model Vektor Autoregressive (VAR) pada data yang diperoleh dari publikasi Statistik Kepariwisataan dari tahun 2008 sampai dengan tahun 2015. Variabel yang digunakan adalah tamu wisatawan mancanegara yang menginap di Hotel Bintang dan Non Bintang. Dengan model Vektor Autoregressive (VAR) dapat digunakan untuk menganalisis data time series pada dua jenis hotel tersebut secara simultan.

Berdasarkan penelitian-penelitian sebelumnya, model VAR memiliki keunggulan antara lain metode ini sederhana yaitu tidak membedakan variabel endogen dan eksogen, estimasinya sederhana, hasil prediksi (forecast) yang diperoleh dengan menggunakan metode ini dalam banyak kasus lebih bagus dibandingkan dengan hasil yang didapat dengan menggunakan model persamaan simultan yang kompleks sekalipun. Selain itu, analisis VAR juga merupakan alat analisis yang sangat berguna, baik dalam memahami adanya hubungan timbal balik (interrelationship) antara variabel-variabel ekonomi, maupun dalam pembentukan model ekonomi terstruktur. 


\section{METODE PENELITIAN}

\section{Sumber Data dan Variabel Penelitian}

Data diperoleh dari publikasi Statistik Kepariwisataan dari tahun 2008 sampai dengan tahun 2015 yang dipublikasikan oleh Dinas Pariwisata Daerah Istimewa Yogyakarta. Pada analisis ini, data yang digunakan yaitu jumlah tamu wisatawan mancanegara per bulan yang menginap di Hotel Bintang dan Non Bintang per bulan di Daerah Istimewa Yogyakarta.

\section{Uji Stasioneritas}

Seperti halnya pada analisis time series univariate (ARIMA), diperlukan asumsi data stasioner baik terhadap mean ataupun variansi. Suatu data dikatakan stasioner jika tidak ada perubahan nilai tengah (rata-rata) dari waktu ke waktu. Kestasioneran mean data ditandai dengan fluktuasi dari data berada di sekitar nilai rata-rata konstan. Dilihat dari plot ACF, nilai autokorelasi dari data stasioner akan turun sampai nol sesudah time lag kedua atau ketiga. Apabila plot deret berkala tidak memperlihatkan adanya perubahan variansi yang jelas dari waktu ke waktu, maka dapat dikatakan deret data tersebut adalah stasioner pada variannya.

Pengujian stasioneritas dapat juga dilakukan dengan uji Augmented Dickey-Fuller Unit Root Test (ADF Test). Jika didapatkan $\mid$ ADF Test Statistik $|<|$ critical value $\mid$ maka dapat dikatakan bahwa data tidak stationer terhadap mean ( $p$-value $>\alpha$ ), sebaliknya jika didapatkan $\mid$ ADF Test Statistik $|>|$ critical value $\mid$ maka dapat dikatakan bahwa data stationer terhadap mean $(p$-value $<\alpha)$.

\section{Identifikasi Model}

Identifikasi model perlu dilakukan untuk mengetahui model. Keadaan tersebut dapat divisualisasikan melalui correlogram (plot ACF dan PACF). Jika ACF meluruh secara eksponensial dan PACF signifikan pada lag p maka proses tersebut merupakan proses AR(p). Jika PACF meluruh secara eksponential dan ACF signifikan pada lag q maka proses merupakan proses MA(q). PACF pada lag k menggambarkan korelasi antara $X_{t+k}$ dengan $X_{t}$ setelah dikurangi dependensi linear dari variable $\operatorname{antara} \mathrm{Z}_{\mathrm{t}+1}, \mathrm{Z}_{\mathrm{t}+2}, \ldots, \mathrm{Z}_{\mathrm{t}+\mathrm{k}-1}$.

\section{Model Autoregressive (AR)}

Model Autoregressive menyatakan suatu ramalan sebagai fungsi nilai-nilai sebelumnya dari runtun waktu tertentu. Suatu proses $Z_{t}$ pada model autoregressive orde pertama yaitu AR(1) menyatakan pengamatan waktu sekarang dipengaruhi pengamatan satu waktu sebelumnya dan unsur error. Model AR(1) dimodelkan dalam persamaan 2.1 sebagai berikut.

$$
Z_{t}=\phi_{1} Z_{t-1}+e_{t}
$$

Dimana $\varepsilon_{\mathrm{t}}$ merupakan unsur error yang menyebar normal dan independen $e_{\mathrm{t}} \sim \mathrm{id} \sim \mathrm{N}\left(0, \sigma^{2}\right)$. Sementara itu, koefisien autoregressive $\phi_{1}$ nilai terbatas antara -1 dan 1(Makridakis,1999, p. 393).

\section{Vector Autoregressive (VAR)}

Model Vector Autoregressive (VAR) merupakan merupakan gabungan dari beberapa model Autoregressive $(A R)$, dimana model membentuk sebuah vektor yang antara variabel variabelnya saling memengaruhi[ ]. Untuk suatu sistem sederhana dengan dua peubah (bivariate model) dengan kelambanan satu, model simultan yang dibentuk adalah sebagai berikut.

$Z_{t}=\Phi_{1} Z_{t-1}+\varepsilon_{t}$

atau dapat dituliskan sebagai berikut. 


$$
\left[\begin{array}{l}
Z_{1 t} \\
Z_{2 t}
\end{array}\right]=\left[\begin{array}{ll}
\phi_{1,11} & \phi_{1,12} \\
\phi_{1,21} & \phi_{1,22}
\end{array}\right]\left[\begin{array}{l}
Z_{1 /(t-1)} \\
Z_{2:(t-1)}
\end{array}\right]+\left[\begin{array}{l}
\varepsilon_{1 t} \\
\varepsilon_{2 t}
\end{array}\right]
$$

atau dapat juga dinyatakan dengan persamaan sebagai berikut.

$$
\begin{aligned}
& Z_{1 t}=\phi_{1,11} Z_{1, t-1}+\phi_{1,12} Z_{2\{(t-1)}+\varepsilon_{1 t} \\
& Z_{2 t}=\phi_{1,21} Z_{1, t-1}+\phi_{1,22} Z_{2 /(t-1)}+\varepsilon_{2 t}
\end{aligned}
$$

\section{Diagnostic Checking}

Diagnostic checking dilakukan untuk menguji kelayakan model. Jika model tidak layak, dilakukan modifikasi model yang biasanya dengan overfitting. Selanjutnya, dari alternatif-alternatif model yang didapatkan dari overfiting tersebut diuji apakah koefisien dari parameter (koefisien AR dan MA) tersebut signifikan dalam model atau tidak. Nilai signifikansi dari parameter-parameter dibandingkan dengan tinkat konfidensi $(\alpha)$. Dikatakan signifikan apabila nilai probabilitas dari AR maupun MA lebih kecil daripada $\alpha$ (biasanya ditetapkan 5\%). Setelah didapatkan model dengan koefisien parameter yang signifikan dilakukan analisis residual.

\section{Analisis Residual}

Asumsi yang dibutuhkan dalam analisis residual sebagai berikut.

\section{No Autocorrelation Residual}

Uji asumsi no autoccorelasi residual dapat dilakukan dengan menggunakan uji Portmanteau.

$H_{0}=\hat{r}_{1}=\hat{r}_{2}=\cdots=\hat{r}_{\mathrm{h}}=0 \quad$ (tidak ada autokorelasi residual sampai lag ke-h)

$H_{1}: x_{1} \neq 0 \quad$ (ada autokorelasi residual sampai lag ke-h)

Statistik uji,

$Q=T(T+2) \sum_{\hat{h}=1}^{h} \frac{\hat{p}_{h}^{2}}{T-\hat{k}}$

Dengan,

$\mathrm{T}$ : banyaknya sisaan

$\hat{r}_{h}:$ autokorelasi antar sisaan

$\mathrm{h}: \mathrm{lag}$

Jika nilai $p$-value $>\propto$, maka $H_{0}$ diterima atau tidak ada komponen autokorelasi yang signifikan hingga lag ke-h, atau dengan kata lain tidak ada autokorelasi residual.

\section{Normalitas Multivariate Residual}

Uji kenormalan residual pada model VAR, umumnya menggunakan uji normalitas Jarque-Berra. Hipotesis untuk uji Jarque-Berra adalah sebagai berikut.

$H_{0}$ : Residual berdistribusi normal

$H_{1}$ : Residual tidak berdistribusi normal

Statistik Uji,

$l B=n \frac{\left(\sqrt{b_{1}}\right)^{2}}{6}+\frac{\left(b_{2}-3\right)^{2}}{24}$

Dengan,

$b_{1}$ : kemencengan

$b_{2}$ : kurtosis 
Atau dengan p-value

$H_{0}$ ditolak jika $P\left(\chi_{(2)}^{2}>J B\right)$ atau $p$-value $<\alpha$, yang berarti bahwa residual tidak berdistribusi normal.

\section{Homoskedastik Residual}

Uji Homoskedastisitas residual menggunakan uji ARCH-LM. Hipotesis untuk uji ARCH adalah sebagai berikut.

$H_{0}$ : Kuadrat residual tidak menunjukkan heteroskedatisitas

$H_{1}$ : Kuadrat residual menunjukkan heteroskedatisitas

Statistik Uji,

$L M=T \times R^{2}$

Dengan,

$T$ = banyaknya pengamatan

$R^{2}=$ koefisien determinasi dari model regresi $\varepsilon_{t}^{2}$

$q$ = banyaknya pengamatan yang memengaruhi

Jika $L M$ lebih besar dari $\chi_{q}^{2}$, mengindikasikan adanya pengaruh ARCH.

\section{HASIL DAN PEMBAHASAN}

Seperti yang telah dibahas pada bab sebelumnya, data yang digunakan dalam studi kasus analisis ini adalah jumlah wisatawan mancanegara yang menginap di Hotel Bintang dan Non Bintang per bulan di Daerah Istimewa Yogyakarta pada bulan Januari 2008 sampai dengan Desember 2015. Plot jumlah wisatawan mancanegara yang menginap di Hotel Bintang digambarkan sebagai berikut.

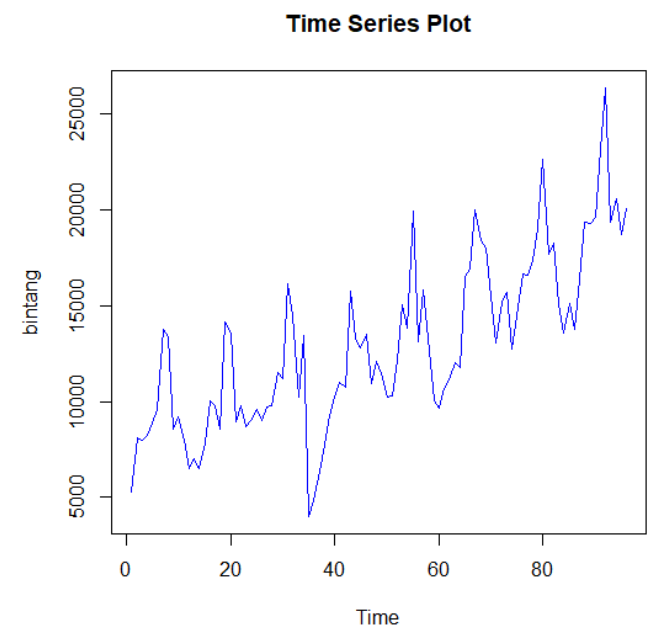

Gambar 1 Plot Jumlah Tamu Mancanegara di Hotel Bintang

Sedangkan untuk plot jumlah wisatawan mancanegara yang menginap di Hotel Non Bintang digambarkan sebagai berikut. 


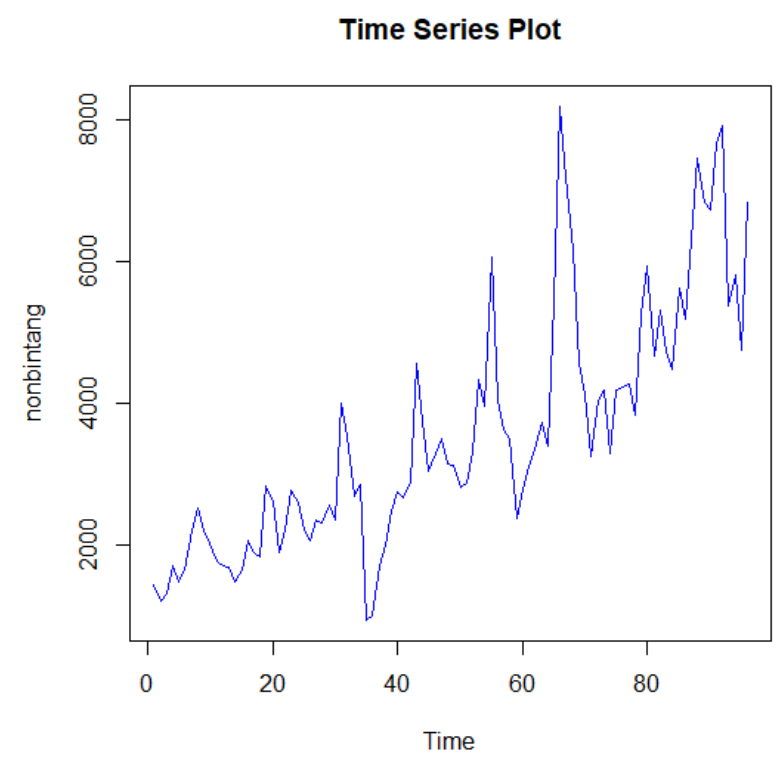

Gambar 2. Plot Jumlah Tamu Mancanegara di Hotel Non Bintang

Uji Korelasi

Untuk mengaplikasikan model multivariate time series yaitu Vector Autoregressive (VAR1) pada data jumlah tamu mancanegara yang menginap di Hotel Bintang dan Non Bintang, perlu dilakukan uji korelasi diantara kedua variabel tersebut. Dengan program R 3.5.1 didapatkan nilai korelasi sebesar 0,9135 . Hal ini berarti kedua variabel tersebut memiliki hubungan yang cukup erat.

\section{Uji Stasioneritas}

Berdasarkan kedua plot pada gambar 1 dan 2 di atas, plot tampak cenderung adanya trend naik, untuk menguji stasioneritas dari kedua data tersebut dilakukan uji Augmented Dickey-Fuller Unit Root Test (ADF Test). Dari uji ADF test didapatkan nilai ADF untuk hotel bintang sebesar -5.76 (p-value : 0.01 ) dan nilai $\mathrm{ADF}$ untuk hotel non bintang sebesar -4.49 (p-value: 0.01). Dengan tingkat signifikansi $\alpha=5 \%$, dari kedua data didapatkan nilai $p$-value $<\alpha$ yang memberikan kesimpulan bahwa kedua data tersebut stasioner terhadap mean sehingga tidak perlu dilakukan differencing.

\section{Identifikasi Model}

Identifikasi model dapat divisualisasikan melalui plot ACF dan PACF. Jika ACF meluruh secara eksponensial dan PACF signifikan pada lag $\mathrm{p}$ maka proses tersebut merupakan proses AR(p). Jika PACF meluruh secara eksponential dan ACF signifikan pada lag q maka proses merupakan proses MA(q). Dari data kedua jenis hotel diperoleh Plot ACF dan PACF sebagai berikut. 

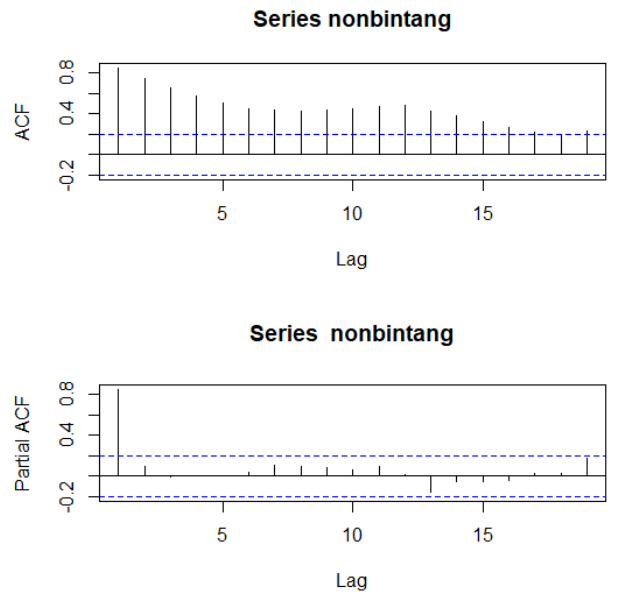

Gambar 3. Plot ACF dan PACF Data Hotel Non Bintang

Berdasarkan plot di atas, terlihat fungsi PACF signifikan hanya pada lag 1(terputus/cut off setelah lag ke 1) dan meluruh menuju nol untuk lag lain yang berarti merupakan model AR(1). Sedangkan untuk fungsi ACF untuk data Hotel Non Bintang terlihat meluruh menuju 0.

Series bintang

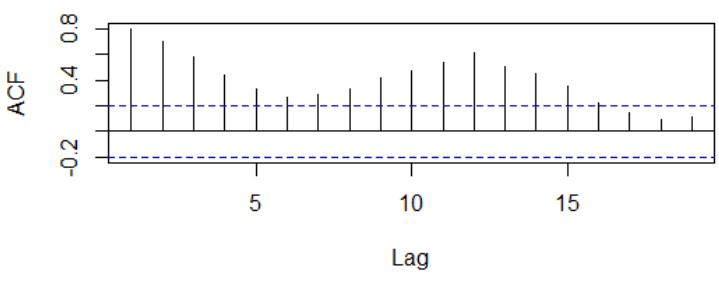

Series bintang

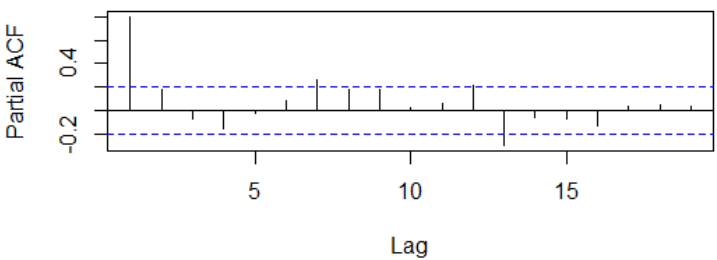

Gambar 4 Plot ACF dan PACF Data Hotel Non Bintang

Berdasarkan plot ACF dan PACF untuk Hotel Non Bintang di atas, terlihat fungsi PACF signifikan hanya pada lag 1 (terputus/cut off setelah lag ke 1) dan meluruh menuju nol untuk lag lain yang berarti merupakan model AR(1). Sedangkan untuk fungsi ACF untuk data Hotel Non Bintang terlihat meluruh (dies down) menuju 0. Kedua data memiliki pola yang hampir sama.

\section{Pemodelan dengan Vector Autoregressive (VAR)}

Model Vector Autoregressive (VAR) merupakan merupakan gabungan dari beberapa model Autoregressive $(A R)$, dimana model membentuk sebuah vektor yang antara variabel variabelnya saling memengaruhi. Berdasarkan hasil identifikasi model di atas, didapatkan model VAR(1), dimana estimasi model VAR(1) pengamatan waktu sekarang dipengaruhi pengamatan satu waktu sebelumnya dan dipengaruhi juga oleh pengamatan variabel lain. Berdasarkan persamaan (2) model VAR(1) untuk dua peubah adalah sebagai berikut. 
$Z_{t}=\Phi_{1} Z_{t-1}+\varepsilon_{t}$

atau dapat dituliskan dalam persamaan (5), (6), dan (7) sebagai berikut.

$$
\left[\begin{array}{l}
Z_{1 t} \\
Z_{2 t}
\end{array}\right]=\left[\begin{array}{ll}
\phi_{1,11} & \phi_{1,12} \\
\phi_{1,21} & \phi_{1,22}
\end{array}\right]\left[\begin{array}{l}
Z_{1,(t-1)} \\
Z_{2,(t-1)}
\end{array}\right]+\left[\begin{array}{l}
\varepsilon_{1 t} \\
\varepsilon_{2 t}
\end{array}\right]
$$

atau dapat juga dinyatakan dengan persamaan sebagai berikut.

$$
\begin{aligned}
& Z_{1 \mathrm{t}}=\phi_{1,11} Z_{1, t-1}+\phi_{1,12} Z_{2 /(t-1)}+\varepsilon_{1 t} \\
& Z_{2 \mathrm{t}}=\phi_{1,21} Z_{1, t-1}+\phi_{1,22} Z_{2 /(t-1)}+\varepsilon_{2 t}
\end{aligned}
$$

\begin{tabular}{|c|c|c|c|c|c|c|}
\hline Persamaan & Variabel & Koefisien & $\begin{array}{l}\text { P-value } \\
\text { (Parsial) }\end{array}$ & $\begin{array}{c}F- \\
\text { value }\end{array}$ & $\begin{array}{c}\text { degree } \\
\text { of } \\
\text { freedom } \\
\text { (df) }\end{array}$ & $\begin{array}{c}\text { P-value } \\
\text { (Simultan) }\end{array}$ \\
\hline \multirow{3}{*}{ Bintang } & c & 3697.3134 & $2.9 \mathrm{e}-05 * * *$ & \multirow{3}{*}{113.3} & \multirow{3}{*}{2} & \multirow{3}{*}{$<2.2 \mathrm{e}-16$} \\
\hline & $\operatorname{bintang}_{\mathrm{t}-1}$ & 0.3957 & $0.004438 * *$ & & & \\
\hline & non bintang ${ }_{\mathrm{t}-1}$ & 1.2091 & $0.000909 * * *$ & & & \\
\hline \multirow{3}{*}{$\begin{array}{c}\text { Non } \\
\text { Bintang }\end{array}$} & $\mathrm{c}$ & 715.80179 & $0.0173 *$ & \multirow{3}{*}{150.2} & \multirow{3}{*}{2} & \multirow{3}{*}{$<2.2 \mathrm{e}-16$} \\
\hline & bintang $_{\mathrm{t}-1}$ & -0.05432 & 0.2574 & & & \\
\hline & non bintang -1 & 1.01191 & $1.63 \mathrm{e}-12 * * *$ & & & \\
\hline
\end{tabular}

Dengan program R didapatkan output sebagai berikut.

Tabel 1 Hasil Estimasi Model VAR(1)

Dengan menggunakan taraf signifikansi $10 \%$, diperoleh bahwa kedua persamaan signifikan simultan (uji-F). Pada uji partial untuk variabel hotel bintang didapatkan nilai $p$-value yang signifikan untuk ketiga koefisiennya. Hal ini berarti untuk hotel bintang dipengaruhi oleh variabel itu sendiri pada periode sebelumnya dan juga dipengaruhi secara positif oleh variabel hotel non bintang pada periode sebelumnya. Pada uji partial untuk variabel hotel non bintang dipengaruhi oleh variabel itu sendiri pada periode sebelumnya dan juga dipengaruhi secara negatif oleh variabel hotel bintang pada periode sebelumnya.

Dalam bentuk matriks, persamaan VAR(1) dapat kita tuliskan sebagai berikut.

$$
\left[\begin{array}{c}
\text { bintangt } \\
\text { non bintangt }
\end{array}\right]=\left[\begin{array}{l}
3697.3134 \\
715.80179
\end{array}\right]+\left[\begin{array}{cc}
0.3957 & 1.2091 \\
-0.05432 & 1.01191
\end{array}\right]\left[\begin{array}{c}
\text { bintang } g_{t-1} \\
\text { non bintangt }-1
\end{array}\right]
$$

Atau dengan persamaan sebagai berikut.

$$
\begin{aligned}
& \quad \text { bintang }_{t}=3697.3134+0.3957 \text { bintang }_{t-1}+1.2091 \text { non bintang } g_{t-1} \\
& \text { non bintang } g_{t}=715.80179-0.05432 \text { bintang } g_{t-1}+1.01191 \text { non bintang } g_{t-1}
\end{aligned}
$$

\section{Diagnostic Checking}

Diagnostic checking dilakukan untuk menguji kelayakan model. Jika model tidak layak, dilakukan modifikasi model. Kelayakan model dalam hal ini dilakukan dengan menguji residual dari model. Asumsi yang dibutuhkan dalam analisis residual sebagai berikut.

\section{No Autocorrelation Residual}

Uji asumsi autokorelasi menggunakan uji Portmanteau. Hipotesis untuk uji Portmanteau adalah sebagai berikut.

$$
H_{0}=\hat{r}_{1}=\hat{r}_{2}=\cdots=\hat{r}_{\mathrm{h}}=0 \quad \text { (tidak ada autokorelasi residual sampai lag ke-h) }
$$




$$
H_{1}: \exists n_{1}^{*} \neq 0 \quad \text { (ada autokorelasi residual sampai lag ke-h) }
$$

Jika nilai $p$-value $>a$, maka $H_{0}$ diterima atau tidak ada komponen autokorelasi yang signifikan hingga lag ke-h.

Output dari program R menunjukkan nilai chi-square sebesar 27.95 (p-value: 0.83). Dengan taraf signifikansi $10 \%$, dari hasil pengujian diperoleh nilai $p$-value $>0,1$ yang berarti bahwa $H_{0}$ tidak ditolak, atau dengan kata lain tidak ada autokorelasi dalam residual (asumsi no autocorrelation residual terpenuhi).

\section{Normalitas Residual}

Uji kenormalan residual pada model VAR, umumnya menggunakan uji normalitas Jarque-Berra. Hipotesis untuk uji Jarque-Berra adalah sebagai berikut.

$H_{0}$ : Residual berdistribusi normal

$H_{1}$ : Residual tidak berdistribusi normal

Hasil uji normalitas residual dengan Jarque-Berra dari model memberikan nilai chi-square sebesar 263.71 ( $p$-value $<0.000$ ). Berdasarkan output di atas didapatkan $p$-value yang sangat kecil ( $p$-value < $\alpha$ ), yang berarti residual tidak berdistribusi normal multivariat.

\section{Homoskedastik Residual}

Uji Homoskedastisitas residual menggunakan uji ARCH-LM (uji Lagrange Multiplier). Hipotesis untuk uji ARCH adalah sebagai berikut.

$H_{0}$ : Kuadrat residual tidak menunjukkan heteroskedatisitas

$H_{1}$ : Kuadrat residual menunjukkan heteroskedatisitas

Statistik Uji,

$L M=T \times R^{2}$ atau digunakan $p$-value

Dengan,

$T$ = banyaknya pengamatan

$R^{2}=$ koefisien determinasi dari model regresi $\varepsilon_{t}^{2}$

$q$ = banyaknya pengamatan yang memengaruhi

Jika $L M$ lebih besar dari $\chi_{q}^{2}$, mengindikasikan adanya pengaruh $\mathrm{ARCH}$.

Dari Program R didapatkan nilai chi-square untuk pengujian ARCH sebesar 67.78 ( $p$-value: 0.94). Berdasarkan output di atas, nilai $p$-value $>\alpha=10 \%$ sehingga $H_{0}$ tidak ditolak, dengan kata lain Kuadrat residual tidak menunjukkan heteroskedatisitas (homoskedastik residual terpenuhi). Hasil diagnostic checking terhadap residual menunjukkan bahwa model VAR(1) untuk studi kasus dengan data jumlah wisatawan di Hotel Bintang dan Non Bintang di Yogyakarta telah memenuhi asumsi no autocorrelation residual, homoskedastik residual, namun belum memenuhi asumsi normalitas residual. Namun demikian, dengan nilai $\mathrm{R}^{2}$ dan Adjusted $\mathrm{R}^{2}$ yang diperoleh dari output estimasi model VAR(1) dapat digunakanakan sebagai bahan pertimbangan mengukur seberapa baik model di atas.

Dari summary model didapatkan nilai $\mathrm{R}^{2}$ sebesar 0.7113 dan Adjusted $\mathrm{R}^{2}$ sebesar 0.705 untuk model hotel bintang dan nilai $\mathrm{R}^{2}$ sebesar 0.7656 dan Adjusted $\mathrm{R}^{2}$ sebesar 0.7605 untuk model hotel non bintang. Nilai $\mathrm{R}^{2}$ dan Adjusted $\mathrm{R}^{2}$ kedua persamaan parsial model VAR(1) cukup tinggi yaitu untuk persamaan variabel Hotel Bintang didapatkan $\mathrm{R}^{2}$ sebesar 71,13\% dan Adjusted $\mathrm{R}^{2} 70,5 \%$, sedangkan untuk persamaan variabel Hotel Non Bintang didapatkan $\mathrm{R}^{2}$ sebesar $76,56 \%$ dan dan Adjusted $\mathrm{R}^{2}$ $70,65 \%$. 
Persamaan yang didapatkan dengan model Vector Autoregressive/ VAR(1) untuk variabel jumlah tamu wisatawan mancanegara di Hotel Bintang dan Hotel Non Bintang di Daerah Istimewa Yogyakarta adalah sebagai berikut.

$$
\begin{gathered}
\text { bintang }_{t}=3697.3134+0.3957 \text { bintang }_{t-1}+1.2091 \text { non bintang } \\
\text { non bintang } \\
\text { nintang }
\end{gathered}
$$

\section{KESIMPULAN DAN SARAN}

\section{Kesimpulan}

Berdasarkan analisis data dengan model Vector Autoregressive (VAR) di atas, dapat disimpulkan sebagai berikut.

1. Korelasi antara variabel variabel jumlah tamu wisatawan mancanegara di Hotel Bintang dan Hotel Non Bintang di Daerah Istimewa Yogyakarta cukup tinggi yaitu sebesar 0,91.

2. Nilai $\mathrm{R}^{2}$ dan Adjusted $\mathrm{R}^{2}$ kedua persamaan parsial model VAR(1) cukup tinggi yaitu untuk persamaan variabel Hotel Bintang didapatkan $\mathrm{R}^{2}$ sebesar $71,13 \%$ dan Adjusted $\mathrm{R}^{2} 70,5 \%$, sedangkan untuk persamaan variabel Hotel Non Bintang didapatkan $\mathrm{R}^{2}$ sebesar $76,56 \%$ dan dan Adjusted $\mathrm{R}^{2} 70,65 \%$.

3. Hasil diagnostic checking terhadap residual menunjukkan bahwa model VAR(1) untuk studi kasus dengan data jumlah wisatawan di Hotel Bintang dan Non Bintang di Yogyakarta telah memenuhi asumsi no autocorrelation residual, homoskedastik residual, namun belum memenuhi asumsi normalitas residual.

\section{Saran}

1. Model VAR(1) tidak memenuhi asumsi residual multivariate normal, untuk penelitian selanjutnya persoalan ini dapat dijadikan bahan untuk mengatasi persoalan tersebut.

2. Adanya kemungkinan terdapat pola seasonal dalam data, dapat digunakan untuk bahan analisis selanjutnya dengan membandingkan dengan model yang mempertimbangkan pola seasonal.

3. Untuk penelitian selanjutnya dapat dibandingkan dengan model lain, dengan model yang terbaik selanjutnya dapat dilakukan forecasting.

\section{UCAPAN TERIMA KASIH}

Terima kasih kepada Ibu Prof. Dr. Budi Nuraini atas masukan dan bimbingannya untuk penelitian ini.

\section{REFERENSI}

Abustan, \& Mahyuddin. (2019). "Analisis Vector Auto Regressive (Var) Terhadap Korelasi Antara Belanja Publik dan Pertumbuhan Ekonomi di Sulawesi Selatan, Tahun 1985-2005”, Jurnal Ekonomi Pembangunan, 10(1).

Makridakis, S. (1999). Metode dan Aplikasi Peramalan (2nd edition). Jakarta: Binarupa Aksara.

Maruddani, D.A.I. \& Diah, S. (2003). "Vector Autoregressive (VAR) untuk Peramalan Harga Saham PT Indofood Sukses Makmur Indonesia Tbk”, Jurnal Sains \& Matematika, 11(1), pp.6-12.

Rosadi, D. (2016). Analisis Runtun Waktu dan Aplikasinya dengan R. Yogyakarta: Gadjah Mada University Press.

Tsay, R. S. (2013). Multivariate time series analysis: with $R$ and financial applications. John Wiley \& Sons. 